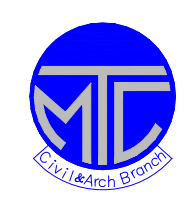

ICCAE

7 th International Conference

Civil \& Architecture

Engineering

Military Technical College

Kobry Elkobbah,

Cairo, Egypt

\title{
ANALYSIS OF STEEL CASED-CONCRETE COMPOSITE COLUMNS USING UNIFIED DESIGN METODOLOGY
}

\author{
E.S.Khalifa* \& A.A. El-Abbasy**
}

\begin{abstract}
The use of steel cased-concrete composite columns and beam-column was widespread in the recent two decades. The utilization of steel cased-concrete composite columns and beam-column was developed to resume the column shutter and thus, reduce the time of construction. The major identification of this steel casedconcrete composite column is to create the concrete confinement and also, make the case tube more stiffened due to the existence of concrete inside the steel case. The composite eliminates the drawbacks of the two materials. The unified design methodology (UDM) was developed, first, for flexural members. This methodology is required for unifying the codes recommendations in simple and rational manner that dose not violates the fundamental principals is an essential requirement. This approach is also, acceptable for design of steel cased-concrete composite columns. The key concept is the definition of the strength reduction factor for concrete inside the case and steel case. The methodology of UDM, sections is divided into three categories while, the steel cased-concrete columns is compression controlled.
\end{abstract}

In this paper, the application of the unified design methodology for steel caseconcrete composite column was performed on circular and square cross section. These circular and square sections are subjected to axial load with minimum eccentricity. The (UDM) proposed in this paper was compared with the experimental test results, recently found on literature. This methodology is compared with the Egyptian Code design philosophy which has first publication for the first time on ECP 203-2007. A parametric study was performed to study the major parameter affecting on the design of steel cased-concrete composite column and beam-column using (UDM).

* E.S. Khalifa Associate Professor - Civil Eng. Dpt. - Higher Technological Institute

${ }^{* *}$ A.A. El-Abbasy Professor - Civil Eng. Dpt. - Higher Technological Institute 


\section{Introduction}

The acceleration of construction work is the major concern on the building construction. The steel cased-concrete composite column and beam-column is one of the contemporary method of construction and also, to take the advantages of the two composite material. The concrete maximize the steel strength by resisting the primary failure mode of buckling, while the steel case improves the confinement of the concrete and thus, the composite carry extra load. The formwork is not required for this case of construction and thus, accelerates the construction time. The discrepancy between the design codes as American Concrete Institute (ACI 1999) [1] and American Institute of Steel Construction-Load and Resistance Factor Design (AISC-LRFD 1999) [2], are described in many references, due to the variation of design methodology between the steel and concrete design codes for column and beam column. This geometric and strength parameters are illustrated [3] as shown on Fig. 1. The steel cased-concrete composite column is added, for the first time, to the Egyptian Code design philosophy (ECP 203-2007) [4].

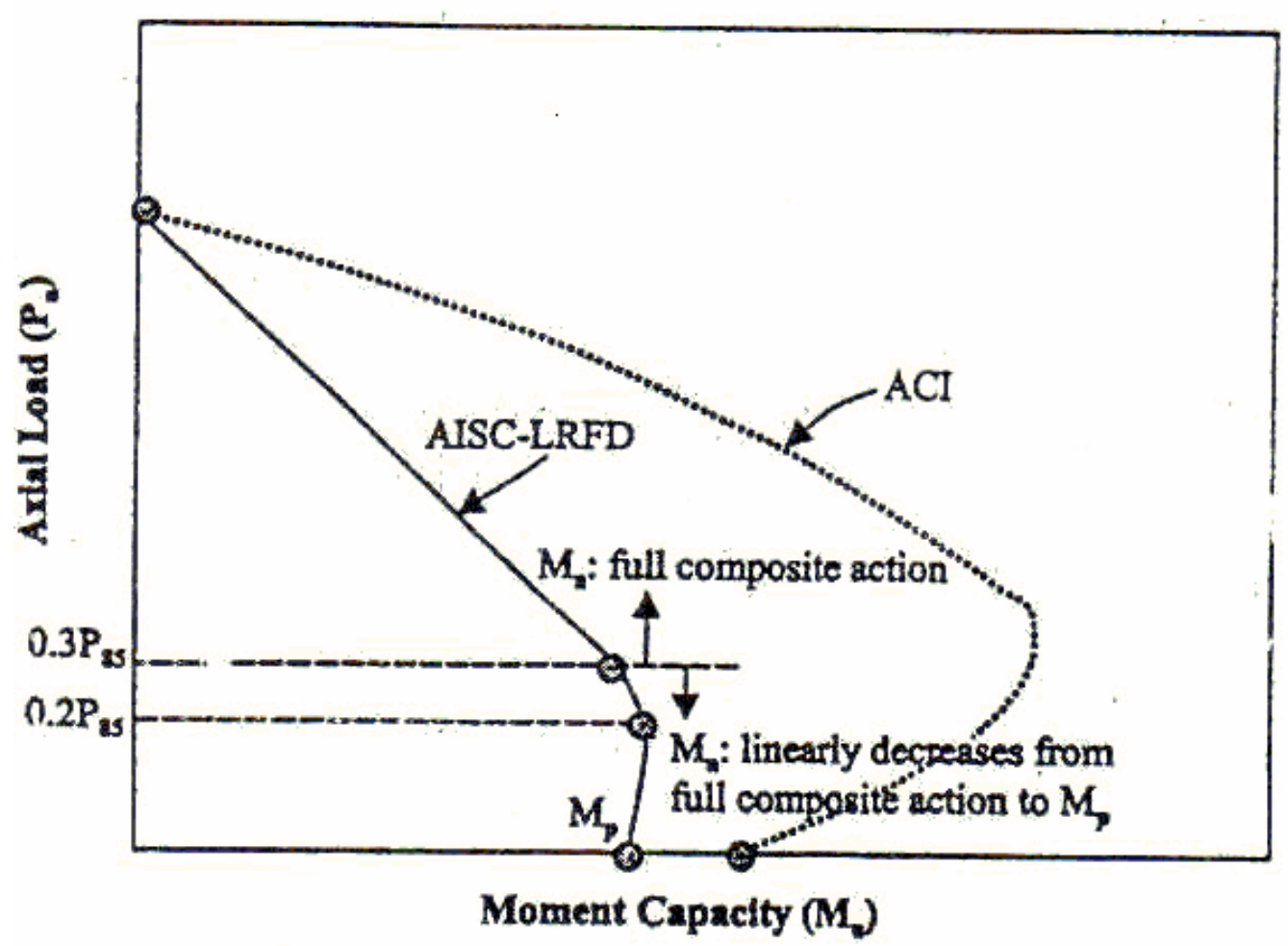

Fig. 1 Different codes predictions for the interaction diagram [3]

For these reasons, the need for unifying the codes recommendations in simple and rational manner that dose not violates the fundamental principals is an essential requirement. The unified design $[5,6]$ recommendations are adopted in this paper to eliminate the codes discrepancies, shown on Fig. 1. The ECP203-2007 Code [4] and computations based on it can be substantially simplified by using strain conditions to define the boundaries of tension controlled behavior and compression controlled behavior, and by a change in the definition of the depth used in setting those boundaries. These new definitions are also used to set the strength reduction factors 
for concrete inside the tube $\left(\gamma_{\mathbf{c}}\right)$ and steel case $\left(\gamma_{\mathbf{s}}\right)$. These design equations are compatible with the philosophy of the ECP for design of column and beam-column. The design of these sections using the unified design approach is compared with the experimental and analytical results with different resources, recently found in literature for box and circular columns and for box beam-columns [3, 7-16]. There are no obtainable experimental results for circular beam-column found in literature. An acceptable agreement between UDM method and the experimental results was clear. The main advantage of the UDM is to insure the behavior of column in compression controlled and the beam-column in tension or in compression or in transition controlled. Parametric study was performed to account for the main parameters on the major aspects of the UDM analytical method.

\section{Confined Compression Model of Concrete}

The steel-case make the concrete inside fully confined and thus the peak compressive strength of concrete has pronounced increase. The adopted stressstrain curve for concrete is chosen in this paper to represent the confined concrete inside the steel-case [17], as shown on Fig. 2. This analytical model [17] can be suitably used for circular and box column and also valid for normal and high-strength concrete. The major concern on the unified design is the peak compressive strength of confined concrete. The peak cylinder compressive strength of confined concrete $\left(\mathbf{f}_{\mathrm{cc}}\right)$ can be determined as function of peak cylinder compressive strength of unconfined concrete $\left(\mathbf{f}_{\mathrm{c}}\right)$ as follows:

$$
\begin{aligned}
& f_{c c}=f_{c}\left[-1.254+2.254 \sqrt{1+7.94 \alpha_{s} \frac{f_{l}}{f_{c}}}-2 \alpha_{s} \frac{f_{l}}{f_{c}}\right] \\
& \alpha_{s}=\left(21.2-0.35 f_{c}\right) \frac{f_{l}}{f_{c}} \quad \text { for } \quad f_{c} \leq 52 M P a \\
& \alpha_{s}=3.10 \frac{f_{l}}{f_{c}} \quad \text { for } \quad f_{c}>52 M P a \\
& f_{l}=0.50 \rho_{s} f_{y}
\end{aligned}
$$

Where $\left(\boldsymbol{\rho}_{\mathbf{s}}\right)$ is the volumetric ratio of the confinement steel-case to the confined concrete inside the steel-case. The confined concrete cube strength $\left(\mathbf{f}_{\mathbf{c u}}^{\mathbf{C}}\right)$ is equal to $\left(1.25 \mathbf{f}_{\mathbf{c c}}\right)$. In this model [17], the confined concrete compressive strength not exceed (2.5) the unconfined concrete. 


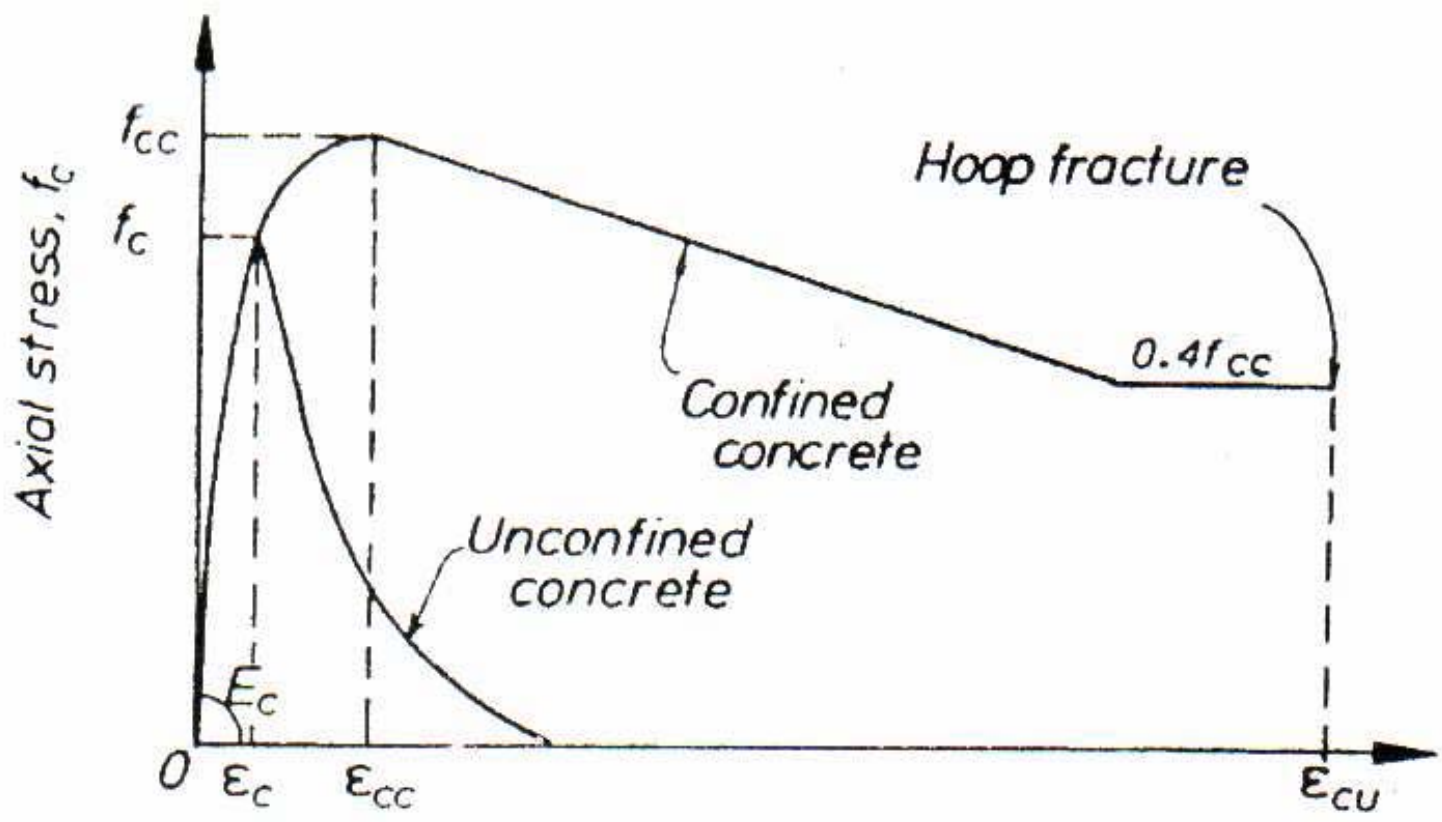

Axial strain. $\varepsilon_{C}$

Fig. 2 Adopted confined and unconfined stress-strain curves for concrete [17]

\section{Local Buckling Control of Steel Case}

The codes previsions $[1,2]$ are relevant in this paper to apply for prevent of local buckling occurred on the steel plates of the steel case. The local buckling of the steel plates is not occurred if the plate dimension (b) to the plate thickness $(\mathbf{t})$ ratio not exceeds the code limitation and defined [1, 2] as follows:

$$
\frac{b}{t} \leq \sqrt{\frac{3 E_{s}}{f_{y}}}
$$

Where $\left(\mathbf{E}_{\mathbf{s}}\right)$ is the modulus of elasticity of steel plate in MPa while, $\left(\mathbf{f}_{\mathbf{y}}\right)$ is the yield stress of the steel plate in MPa. If the local bucking is occurred in the steel plate the reduction of the plate area of local buckling should be eliminated and thus, the plate dimension (b) should be reduced [11] to $\left(\mathbf{b}_{\mathbf{e}}\right)$ as shown on Fig. 3. The effective dimension with incorporating local buckling of the steel case is shown on Fig. 2-b for the case of axial load with minimum eccentricity while, Fig. 2-c shows the case of eccentric load with introduce of the local buckling. The ratio between the reduced dimensions of the buckled plate $\left(\mathbf{b}_{\mathbf{e}}\right)$ to the original dimension of the steel plate $(\mathbf{b})$ can be expressed as: 


$$
\frac{\mathbf{b}_{\mathbf{e}}}{\mathbf{b}} \leq \lambda \sqrt{\frac{\mathbf{f}_{\mathbf{e}}}{\mathbf{f}_{\mathbf{y}}}}
$$

Where constant $(\lambda)$ can be predicted to account for best fit of the experimental results [11] as (0.65). The $\left(\mathbf{f}_{e}\right)$ is the local buckling stress and can be calculated as follows:

$$
f_{e}=\frac{K \pi^{2} E_{s}}{12\left(1-v^{2}\right)(b / t)^{2}}
$$

The local buckling coefficient $(K)$ is taken $[11,16]$ as $(10.31)$ for this case study.

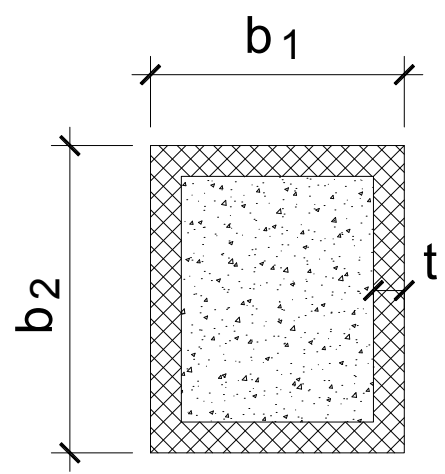

a) Without Local Buckling

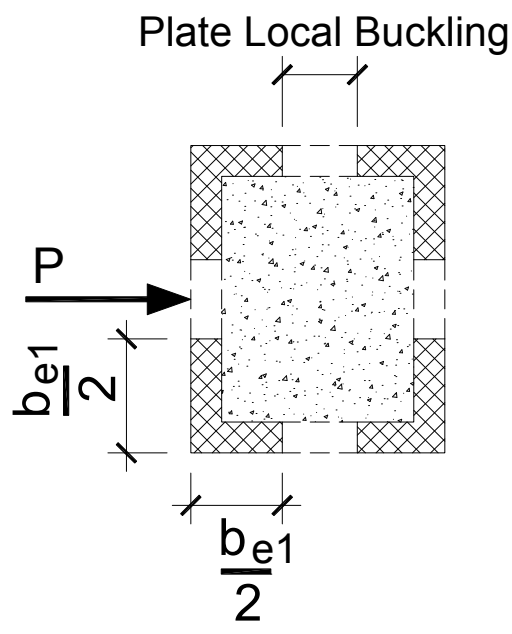

b) With Local Buckling (Due to Axial Load)

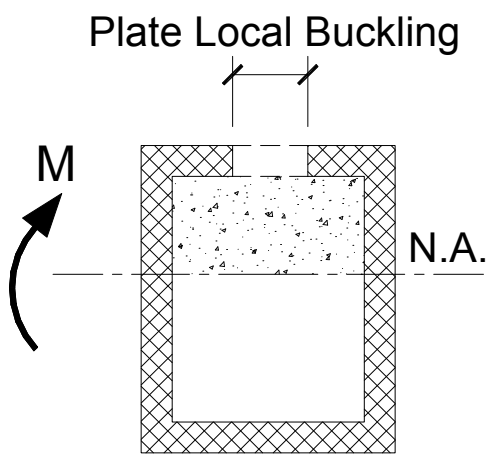

c) With Local Buckling

(Due to Moment)

\section{Fig. 3 Effect of local buckling on the steel plates of steel-case}

\section{Conception of the Unified Design Approach}

The following concepts were defined $[6,18]$ and they were accepted by the ACI Code [1]. Tension controlled behavior is defined to include members that have large tensile strains in the steel case at the ultimate limit state. On the other hand, compression controlled behavior is defined to include members whose ultimate capacity is controlled primarily by crushing of concrete at the assumed maximum compressive strain of $\left(\varepsilon_{\mathrm{cu}}\right)$, which is suitable for box and circular column subjected to concentric load. Also, an intermediate range of behavior between the above limits may be defined in the following subsections. 


\subsection{Strength Reduction Factors for Concrete and Steel Case}

The strength reduction factor for concrete $\left(\gamma_{c}\right)$ is chosen to be 1.5 for tension controlled sections, while it is recommended to be 1.7 or 1.82 for compression controlled sections with circular steel case or box steel case, respectively. Also, the strength reduction factor for steel-case $\left(\gamma_{\mathbf{s}}\right)$ is 1.15 for tension controlled sections, while it is chosen to be 1.3 or 1.4 for compression controlled sections with circular steel case or box steel case, respectively. If the section is in the transition zone between tension and compression controlled behavior the values of $\left(\gamma_{\mathbf{c}}\right)$ and $\left(\gamma_{\mathbf{s}}\right)$ are obtained from the linear equations between the two limits as shown in Fig. 4 or the following equations. If the strength reduction factors for materials are chosen to be function of the net tensile strains, the following equations may be used:

$$
\begin{array}{ll}
\gamma_{\mathrm{c}}=1.8125-62.50 \varepsilon_{\mathrm{t}} & \text { (circular steel case) } \\
\gamma_{\mathrm{c}}=2.000-100.00 \varepsilon_{\mathrm{t}} & \text { (box steel case) } \\
\gamma_{\mathrm{s}}=1.384-46.875 \varepsilon_{\mathrm{t}} & \text { (circular steel case) } \\
\gamma_{\mathrm{c}}=1.541-78.125 \varepsilon_{\mathrm{t}} & \text { (box steel case) }
\end{array}
$$

These equations can be rewritten in terms of the ratio of the neutral axis depth to the extreme depth $\left(\mathbf{c} / \mathbf{d}_{\mathbf{t}}\right)$ as follows:

$$
\begin{array}{ll}
\gamma_{c}=1.200-0.80\left(c / d_{t}\right) & (\text { circular steel case) } \\
\gamma_{c}=1.020-1.28\left(c / d_{t}\right) & (\text { box steel case) } \\
\gamma_{s}=0.925-0.60\left(c / d_{t}\right) & (\text { circular steel case) } \\
\gamma_{c}=0.775+\left(c / d_{t}\right) & (\text { box steel case) }
\end{array}
$$

Moreover, the determination of the strength reduction factors of materials $\left(\gamma_{c}\right)$ for concrete in compression, $\left(\gamma_{\mathbf{s}}\right)$ for steel case. The term "tension controlled" is suitable for the box columns subjected to eccentric load and known as beam-column. These values are illustrated in Table 1 and Fig. 4 . It is clear that tension controlled sections may be designed using smaller values of $\left(\gamma_{\mathrm{c}}\right),\left(\gamma_{\mathrm{s}}\right)$ because they are expected to give enough warning of impending failure prior to actual collapse and since they are less sensitive to variation in material strengths, mainly to the concrete strength. For the circular column subjected to concentric load its recommended in this paper to use the partial safety factors of spiral reinforced column, as shown on Fig. 4. 
Table (1) Net tensile strains, the neutral axis depth ratio, and strength reduction factors for different behaviors at failure

\begin{tabular}{|c|c|c|c|c|}
\hline Behavior & $\varepsilon_{\mathrm{t}}$ & $\mathbf{c} / \mathbf{d}_{\mathrm{t}}$ & $\gamma_{\mathrm{c}}$ & $\gamma_{\mathrm{s}}$ and $\gamma_{\mathrm{ct}}$ \\
\hline Tension controlled & $\geq 0.005$ & $\leq 0.375$ & 1.50 & 1.15 \\
\hline Transition & $\begin{array}{c}<0.005 \& \\
>0.0018\end{array}$ & $\begin{array}{c}<0.625 \& \\
>0.375\end{array}$ & \multicolumn{2}{|c|}{$\begin{array}{c}\text { Straight lines } \\
\text { (see Fig. 4 \& Eq }\end{array}$} \\
\hline $\begin{array}{c}\text { Compression controlled } \\
\text { (with circular steel case) }\end{array}$ & $\leq 0.0018$ & $\geq 0.625$ & 1.70 & 1.30 \\
\hline $\begin{array}{c}\text { Compression controlled } \\
\text { (with box steel case) }\end{array}$ & $\leq 0.0018$ & $\geq 0.625$ & 1.82 & 1.40 \\
\hline
\end{tabular}

$\gamma_{c} \& \gamma_{s}$

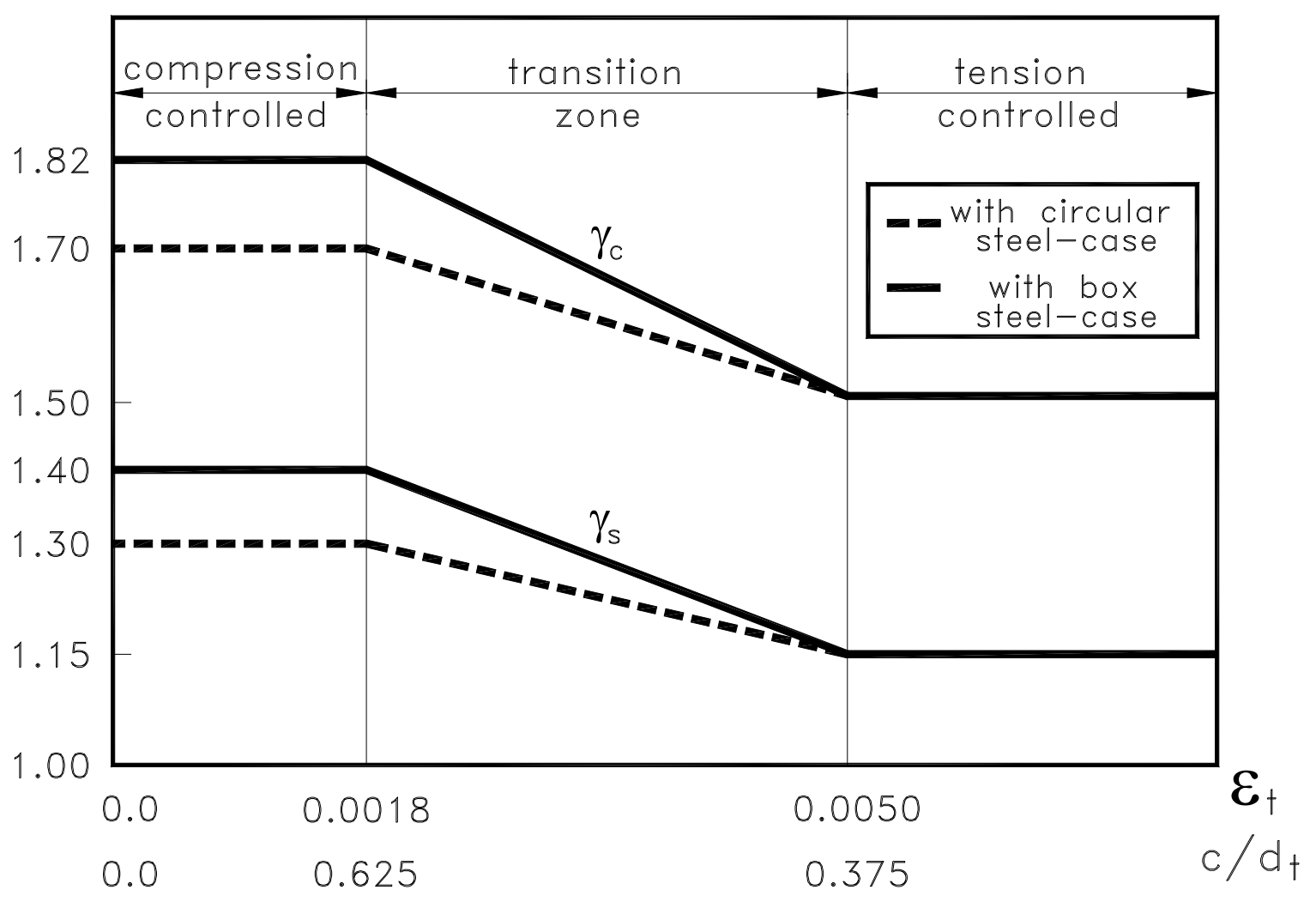

Fig. 4 Variation of $\gamma_{c}$ and $\gamma_{s}$ wit net tensile strain $\left(\varepsilon_{t}\right)$ and with the neutral axis depth to the extreme depth ratio $\left(c / d_{t}\right)$

\subsection{The Extreme Depth}

In calculations of the ultimate capacity of a certain section, the concept of effective depth (d) is used in the ECP203-2007 Code. It is defined as the distance measured 
from the maximum compression fiber at the centroid of the compression steel plate to the tension steel plate centroid. Thus, determination of the centroid of tension steel plate is a must.

\subsection{The Net Tensile Strain}

The ECP203-2007 Code defines the maximum compressive strain at the ultimate limit state $\left(\varepsilon_{\mathrm{cu}}\right)$ to be 0.003 for sections subjected to flexure or flexure with axial force on the condition that a part of the section is under tension. The tensile strains in the tension-side steel plate may be used as a measure of the type of the behavior at the ultimate limit state (tension or compression controlled).

\subsection{Adopted Definition of Tension and Compression Controlled Sections}

The tension controlled sections are defined as those having the net tensile strain at the ultimate limit state not less than 0.005 for steel cased-concrete composite sections. This gives the same minimum amount of curvature, for a given depth, for all tensioned controlled flexural members. Using $\left(\mathbf{d}_{\mathbf{t}}\right)$ is proposed because the strain at the extreme depth is a better indicator for ductility, crack width, and cracking potential of the concrete inside the steel case. Choosing the 0.005 strain limit, which is higher than the implied by the Code, is due to the use of the 0.005 limit produces more reasonable-looking interaction diagrams.

The boundary of compression controlled failure can be defined by the aid of balanced failure conditions which are defined in terms of strain. The ECP203-2007 Code definition uses a strain of [ $\left.\mathbf{f}_{\mathbf{y}} /\left(\mathbf{2 0 0 0 0 0} \gamma_{\mathrm{s}}\right)\right] \mathrm{MPa}$ [0.0014 for other steel $\left(\gamma_{\mathrm{s}}=\mathbf{1 . 4}\right)$ for Grade $400 / 600$ steel] for the tensile strain at balanced condition in steel casedconcrete.

For simplicity, the author presents another definition of compression controlled sections as those in which the net tensile strain at the ultimate limit state at the depth $\left(\mathbf{d}_{\mathbf{t}}\right)$ is less than or equal to 0.0018 . The reasons for choosing a net tensile strain limit of 0.0018 instead of 0.0014 is desirable, for simplicity, to have a single limit for all grades of steel. The proposed limit of 0.0018 is a compromise between the yield strain for Grade 400/600 and for higher grades of reinforcement (if any).

\section{Proposed UDA Model for Steel Cased-Concrete Composite Columns and Beam-Columns}

The following subsections described the proposed UDA model for steel casedconcrete composite columns and beam-columns. The proposed UDA equations are developed to drive the interaction diagram for the steel cased-concrete composite. These design equations are matched with the same philosophy (ECP 203-2007) of strain-compatibility approach for design of composite beam-columns and columns. 


\subsection{Unified Equations for Columns with Minimum Eccentricity}

The pure axial force in this paper is proposed as modified version of the ultimate axial load $(\mathbf{P})$ equation given in [1]. The proposed equation is given as function of confined concrete compressive cube strength $\left(\mathbf{f}_{\mathbf{c u}}^{\mathbf{C}}\right)$, yield strength of steel case $\left(\mathbf{f}_{\mathbf{y}}\right)$, the steel case thickness $(\mathbf{t})$ and column dimensions $\left(\mathbf{b}_{1}, \mathbf{b}_{\mathbf{2}}\right)$ as follows:

$$
\mathbf{P}=0.67\left(f_{c u}^{c} / \gamma_{c}\right)\left(b_{1}-2 t\right)\left(b_{2}-2 t\right)+\left(f_{y} / \gamma_{s}\right)\left(b_{1}+b_{2}-2 t\right) 2 t
$$

The equation (9) is based on the composite column without occurrence of the local buckling inside the plate. For the circular steel cased concrete column it is provided to use the strength reduction factors for spiral while, using strength reduction factor for other reinforcement for box columns. The value of axial force allows minimum eccentricity of the greater value of $\left(\mathbf{0 . 0 5} \mathbf{b}_{\mathbf{2}}\right)$ or $20 \mathrm{~mm}$. In the case of pure axial load concrete has an ultimate strain equal to (0.002).

\subsection{Boarder between Compression Controlled and Transition Zone}

The border limit between compression controlled and the transition zone can be established and calculated based on the concept known as balanced load. The stress configuration and methodology and philosophy are based on the strain compatibility approach [4], as shown on Fig. 5. This boarder is occurred when the concrete strain on the inside face of top flange is $(0.003)$ and the tensile strain at the centroid of the lower flange is yield strain of the steel plate $\left(\boldsymbol{\varepsilon}_{\mathbf{y}}\right)$ or can be approximately taken as $(0.0018)$. The stain compatibility can determine the border depth of the neutral axes $\left(\mathbf{C}_{\mathbf{b}}\right)$ as:

$$
C_{b}=\frac{0.003 b_{2}}{\varepsilon_{y}+0.003}
$$

The compressive stress in the concrete $\left(\mathbf{C}_{c}\right)$ can be derived as function of the equivalent stress block of the confined concrete as follows:

$$
C_{c}=\left[0.67 f_{c u}^{c} / \gamma_{c}\right] a\left(b_{1}-2 t\right)
$$

The top and bottom flanges compressive force $\left(\mathbf{C}_{f}\right)$ and tensile force $\left(\mathbf{T}_{\mathbf{f}}\right)$ can be derived as given:

$$
\mathbf{T}_{\mathbf{f}}=\mathbf{C}_{\mathbf{f}}=\left(\mathbf{f}_{\mathbf{y}} / \gamma_{\mathrm{s}}\right) \mathbf{b}_{\mathbf{1}} \mathbf{t}
$$

The force in compression web is composed of plastic part $\left(\mathbf{C}_{1}\right)$ over depth equal $(\mathbf{x})$ and elastic part $\left(\mathbf{C}_{2}\right)$ over depth equal to $\left(\mathbf{C}_{\mathrm{b}}-\mathbf{x}\right)$ by the following equations: 


$$
\begin{aligned}
& \mathbf{C}_{1}=2\left(\mathbf{f}_{\mathbf{y}} / \gamma_{s}\right) \mathbf{x t} \\
& \mathbf{C}_{2}=\left(\mathbf{f}_{\mathbf{y}} / \gamma_{s}\right)\left(\mathbf{C}_{b}-\mathbf{x}\right) t \\
& x=2 C_{b}-d_{t}
\end{aligned}
$$

The tension force $\left(\mathbf{T}_{\mathbf{1}}\right)$ in the web can be derived as:

$$
\mathbf{T}_{1}=\mathbf{C}_{2}=\left(\mathbf{f}_{\mathbf{y}} / \gamma_{\mathrm{s}}\right)\left(\mathbf{C}_{\mathbf{b}}-\mathbf{x}\right) \mathbf{t}
$$

The resultant axial force $(\mathbf{P})$ and the resultant moment about the top compression flange $(\mathbf{M})$, as function of compressive $\left(\mathbf{C}_{\mathbf{i}}\right)$ and tensile $\left(\mathbf{T}_{\mathbf{i}}\right)$ forces on the whole section and the distances of the compressive $\left(\mathbf{y}_{\mathrm{Ci}_{\mathrm{i}}}\right)$ and tensile $\left(\mathbf{y}_{\mathrm{Ti}_{\mathrm{i}}}\right)$ forces of the composite beam-column from the top fibers, can be given as:

$$
\mathbf{P}=\sum_{\mathbf{i}=\mathbf{1}}^{\mathbf{n}} \mathbf{C}_{\mathbf{i}}+\sum_{\mathbf{i}=\mathbf{1}}^{\mathbf{n}} \mathbf{T}_{\mathbf{i}}
$$

$$
\mathbf{M}=\sum_{\mathbf{i}=1}^{\mathbf{n}} \mathbf{C}_{\mathbf{i}} \mathbf{y}_{\mathbf{C i}}+\sum_{\mathbf{i}=\mathbf{1}}^{\mathbf{n}} \mathbf{T}_{\mathbf{i}} \mathbf{y}_{\mathbf{T i}}
$$

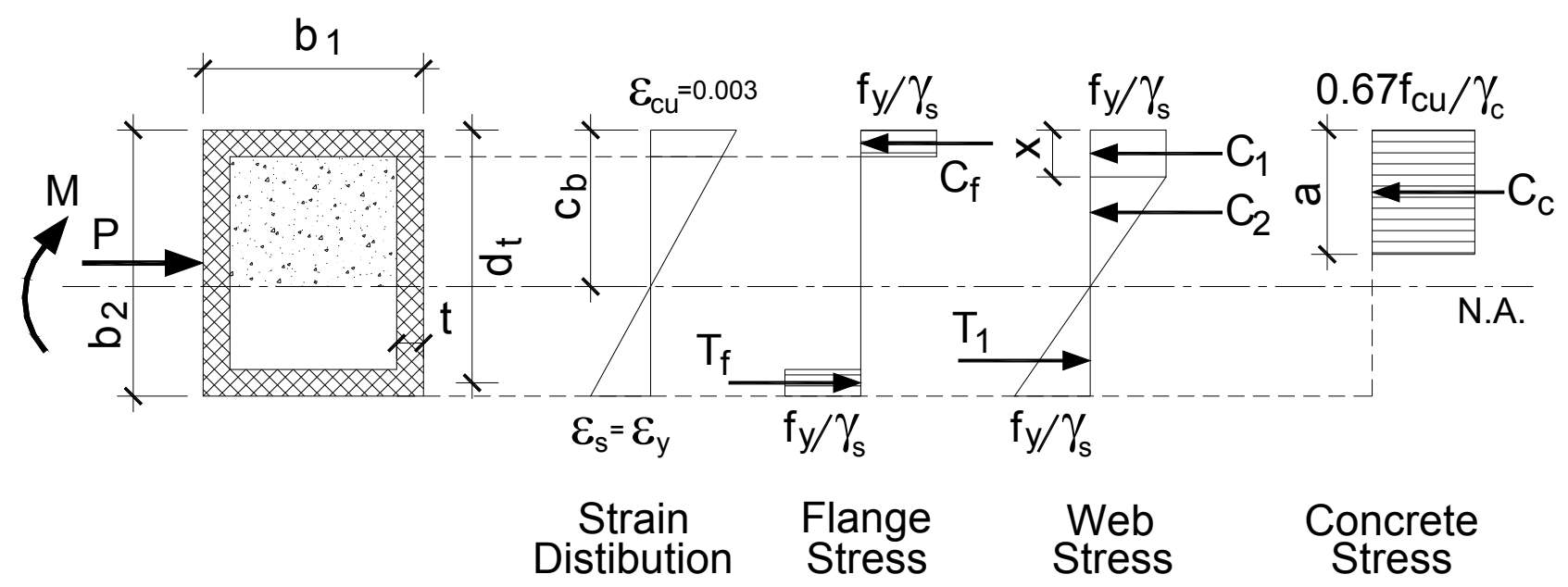

Fig.5 Boarder between Compressions Controlled and Transition Zone 


\subsection{Compression Controlled Design}

For situations when the depth required for tension control behavior can not be provided, the design of flexural members may fall either in the compression control region or in the transition zone. The strain level on the tension side $\left(\varepsilon_{\mathrm{t}} \leq \mathbf{0 . 0 0 1 8}\right),\left(\gamma_{\mathrm{c}}\right.$ $=1.82)$ and $\left(\gamma_{s}=1.4\right)$. The compression controlled configuration is shown on Fig. 6. The stress level $\left(\mathbf{f}_{\mathbf{s}}\right)$ in this case can be evaluated from the strain compatibility. The tension force on the tension flange $\left(\mathbf{T}_{\mathbf{f}}\right)$ and in the web $\left(\mathbf{T}_{\mathbf{1}}\right)$ can be expressed as:

$$
\begin{aligned}
& T_{f}=f_{s} b_{1} t \\
& T_{1}=f_{s}\left(d_{t}-c\right) t \\
& f_{s}=E_{s} \varepsilon_{s}
\end{aligned}
$$

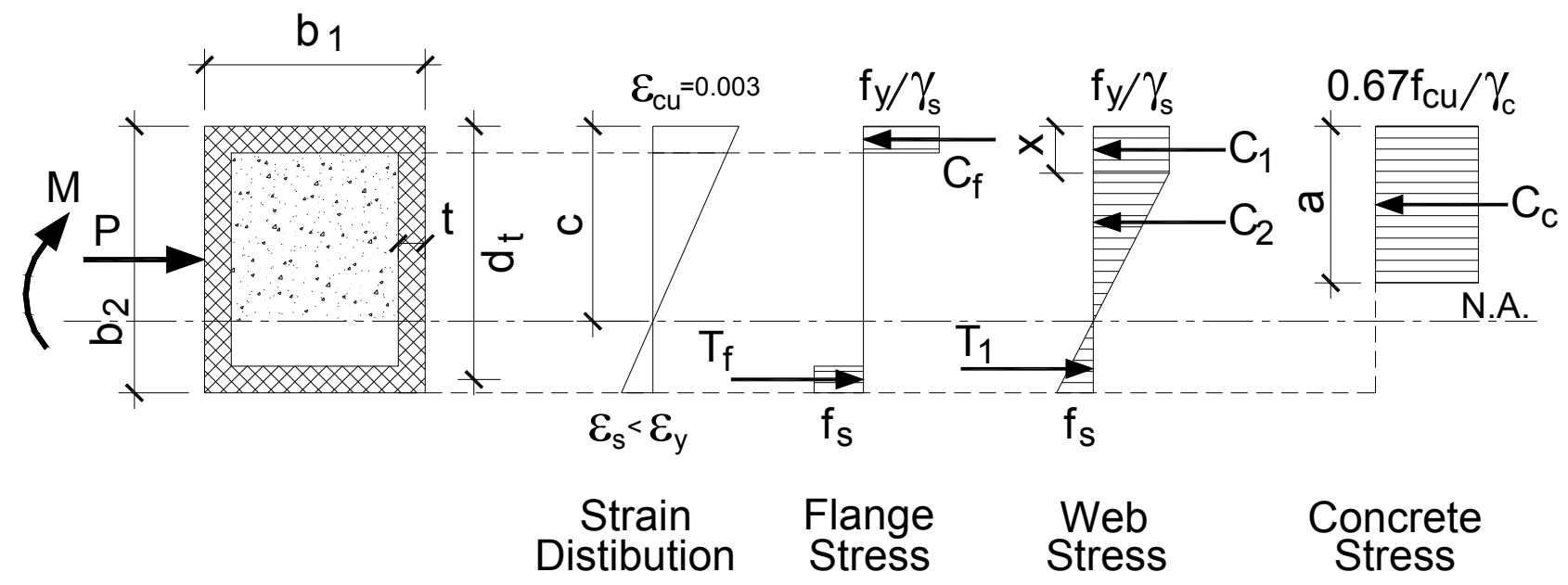

\section{Fig. 6 Compression Controlled definition of steel cased-concrete box with eccentric load}

\subsection{Tension Controlled Design}

For situations when the depth required for tension control behavior can be provided the design of flexural members fall in the tension control region. The strain level on the tension side $\left(\varepsilon_{t} \geq 0.005\right),\left(\gamma_{c}=1.50\right)$ and $\left(\gamma_{s}=1.15\right)$. The tension controlled configuration is shown on Fig. 7 . The tension force on the tension flange $\left(\mathbf{T}_{\mathbf{f}}\right)$ can be calculated as proposed in equation (12). The tensile forces in flange can be composed of plastic part $\left(\mathbf{T}_{\mathbf{1}}\right)$ and elastic part $\left(\mathbf{T}_{\mathbf{2}}\right)$ as: 


$$
\begin{aligned}
& \mathbf{T}_{1}=2\left(\mathbf{f}_{\mathbf{y}} / \gamma_{\mathrm{s}}\right)\left(\mathbf{d}_{\mathrm{t}}-2 \mathbf{C}-\mathbf{x}\right) \mathbf{t} \\
& \mathbf{T}_{2}=\left(\mathbf{f}_{\mathbf{y}} / \gamma_{\mathrm{s}}\right)(\mathbf{C}-\mathbf{x}) \mathbf{t}
\end{aligned}
$$

The resultant axial force $(\mathbf{P})$ and the resultant moment $(\mathbf{M})$ can be calculated as proposed in equations $(17,18)$ respectively.

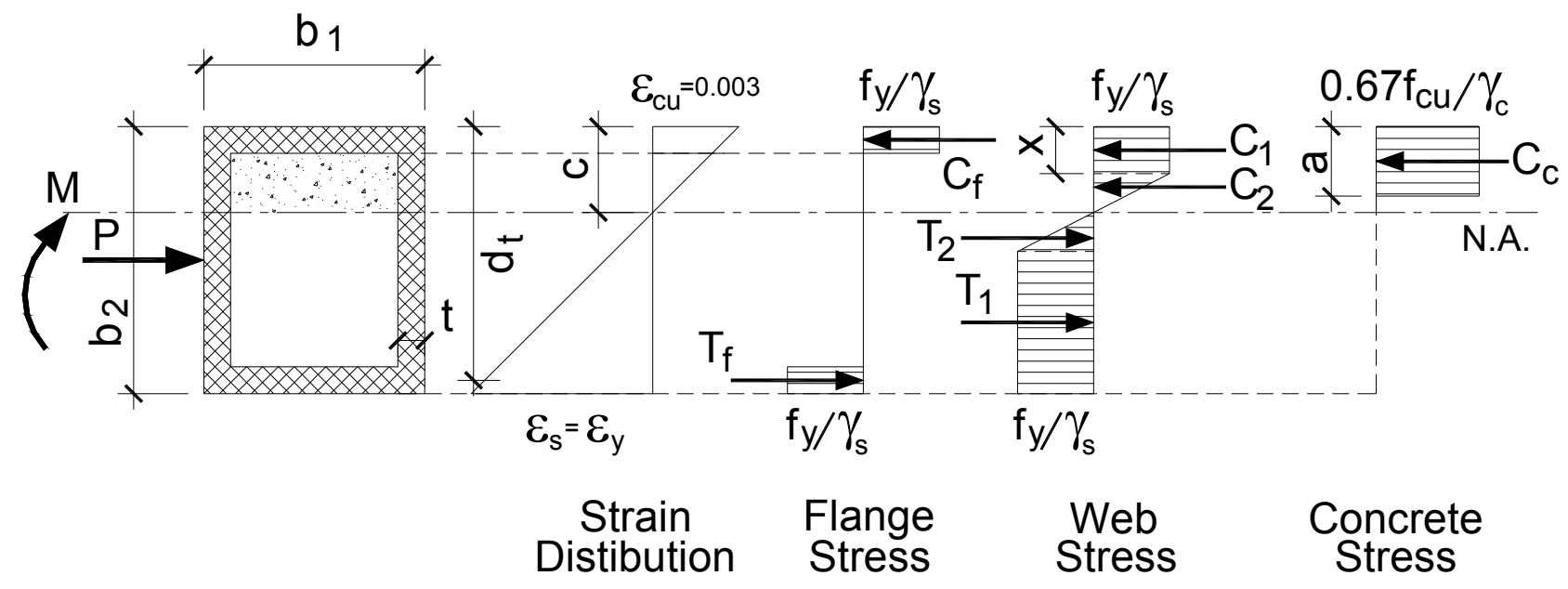

Fig. 7 Tension Controlled definition of steel cased-concrete box with eccentric load

\subsection{Designs in the Transition Zone}

The following equations describe the relation between the extreme tension strain $\left(\varepsilon_{t}\right)$ in terms of $\left(\mathbf{c} / \mathbf{d}_{\mathbf{t}}\right)$ and $\left(\gamma_{\mathbf{c}}\right)$ or $\left(\gamma_{\mathbf{s}}\right)$.

$$
c / d_{t}=\left(\gamma_{c}-1.02\right) / 1.28=\left(\gamma_{s}-0.775\right)
$$

The design equations for the transition zone is the same as proposed in subsection (5.2) for the border between compression controlled and transition except changing of the strength reduction factors as given in Table 1. and in Fig. 4.

\section{Validation Study of the UDM}

The validation study in this paper includes circular steel cased-concrete composite sections subjected to concentric axial load and box steel cased-concrete composite section subjected to concentric and eccentric axial load. There are shortcomings on 
the experimental results available in literature for eccentric circular steel casedconcrete composite sections. The comparison between the experimental results from different resources [7] and the results of proposed analytical UDM model are shown in Table 2. As shown from Table 2. this comparison seems to be in good correlation.

\section{Table (2) Comparison between experimental results and proposed analytical UDM model}

\begin{tabular}{|c|c|c|c|c|c|c|c|c|}
\hline Sam. & Diam. & $\begin{array}{c}\text { Area } \\
\text { steel } \\
\text { No. }\end{array}$ & $\begin{array}{c}\text { Area } \\
\text { Conc. }\end{array}$ & $\mathbf{f}_{\mathbf{c}}$ & $\mathbf{f}_{\mathbf{y}}$ & $\mathbf{P}$ (test) & $\mathbf{P}$ (UDA) & $\begin{array}{c}\mathbf{P} \text { (UDA) } \\
\mathbf{P} \text { (test) }\end{array}$ \\
\hline 1 & 216 & 2722 & 33870 & 22.90 & 291.65 & 1650.2 & 1565.9 & 0.95 \\
\hline 2 & 216 & 3954 & 32645 & 22.90 & 391.64 & 2441.9 & 2211.9 & 0.91 \\
\hline 3 & 95 & 1051 & 6038 & 24.06 & 337.86 & 462.59 & 452.07 & 0.98 \\
\hline 4 & 121 & 1380 & 10064 & 21.10 & 311.65 & 720.57 & 592.36 & 0.82 \\
\hline 5 & 38.1 & 309 & 832 & 27.85 & 524.02 & 109.86 & 123.09 & 1.12 \\
\hline 6 & 50.8 & 258 & 1767 & 27.85 & 524.02 & 120.54 & 134.61 & 1.11 \\
\hline 7 & 76.2 & 380 & 4174 & 27.23 & 524.02 & 320.25 & 293.16 & 0.92 \\
\hline 8 & 355.6 & 5206 & 94193 & 20.96 & 276.49 & 3518.4 & 3538.80 & 1.01 \\
\hline 9 & 127.2 & 638 & 12064 & 66.19 & 370.95 & 1285.5 & 1165.52 & 0.91 \\
\hline 10 & 127 & 1148 & 11548 & 66.19 & 370.95 & 1303.3 & 1268.98 & 0.97 \\
\hline 11 & 101.6 & 961 & 7161 & 34.13 & 605.38 & 818.43 & 748.53 & 0.92 \\
\hline 12 & 120.9 & 1503 & 10000 & 34.41 & 451.62 & 1156.5 & 945.94 & 0.82 \\
\hline 13 & 152.4 & 1477 & 16774 & 20.90 & 415.08 & 938.53 & 903.37 & 0.96 \\
\hline 14 & 76.45 & 406 & 4193 & 24.96 & 363.37 & 244.64 & 242.38 & 0.99 \\
\hline 15 & 114.3 & 1109 & 9161 & 28.96 & 413.70 & 733.92 & 679.7 & 0.93 \\
\hline 16 & 127 & 942 & 11741 & 35.16 & 289.60 & 636.06 & 718.28 & 1.12 \\
\hline 17 & 152.4 & 735 & 17483 & 21.03 & 330.96 & 680.54 & 639.95 & 0.94 \\
\hline 18 & 88.9 & 1522 & 4683 & 40.06 & 399.91 & 613.82 & 699.26 & 1.13 \\
\hline
\end{tabular}

A computer program has been performed to generate the interaction diagram of steel case-concrete composite beam-column, based on the UDM design equations generated in this paper. The validation of the box steel cased-concrete interaction diagram, generated using UDM, with experimental results from two different resources $[3,11]$ is presented in this section. The first validation study [3] is beamcolumn section of dimensions $305 \mathrm{~mm} \times 305 \mathrm{~mm}$ with $9.6 \mathrm{~mm}$ plate thickness. The concrete strength $\left(\mathbf{f}_{\mathrm{c}}\right)$ is $110 \mathrm{MPa}$ while, the yield stress of the steel plates is 269 $\mathrm{MPa}$. Good agreement between analytical and experimental results is shown in Fig. 8. The second validation study is beam-column section of dimensions $126 \mathrm{~mm} \times 126$ $\mathrm{mm}$ with $3.0 \mathrm{~mm}$ plate thickness. The concrete strength $\left(\mathbf{f}_{\mathrm{c}}\right)$ is $50 \mathrm{MPa}$ while, the 
yield stress of the steel plates is $300 \mathrm{MPa}$. An acceptable conformity between analytical and experimental results is shown in Fig. 9.

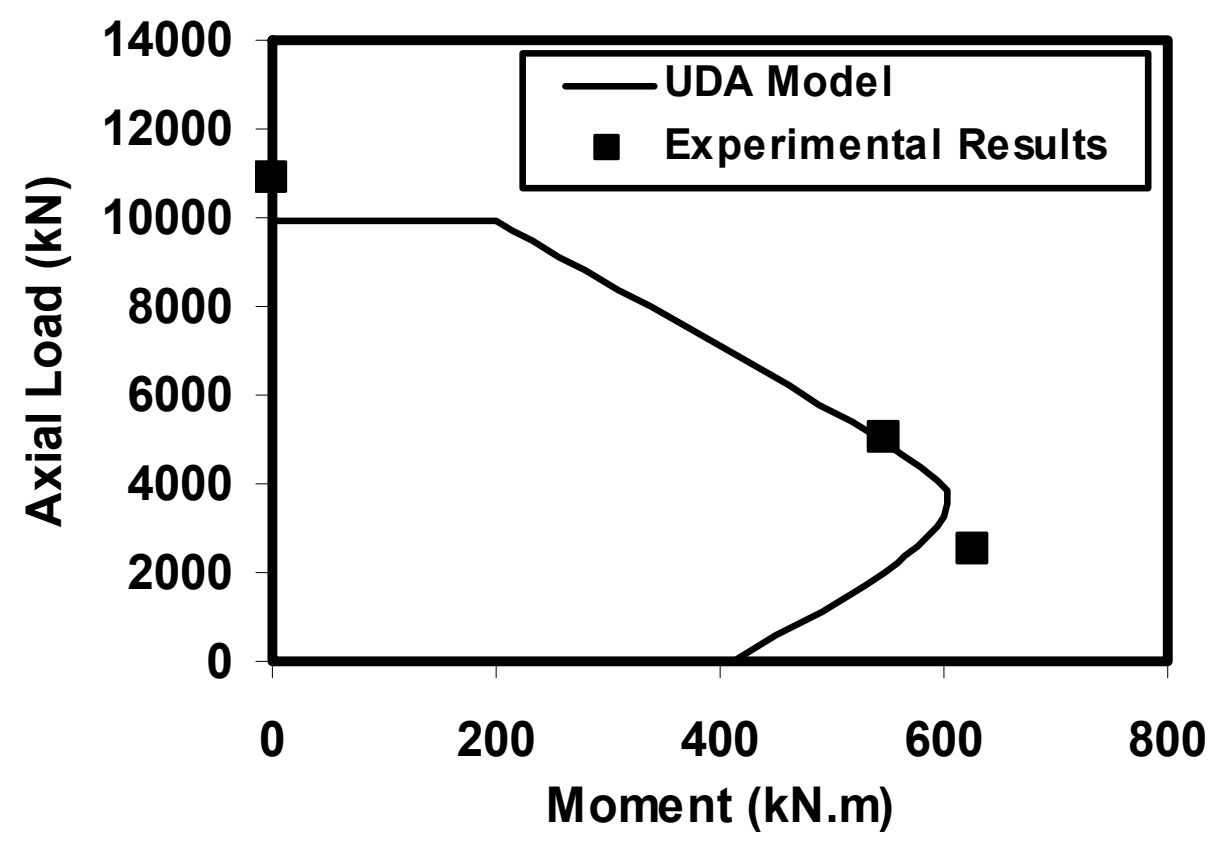

Fig. 8 Validation of the interaction diagram generated by UDM with experimental results [3]

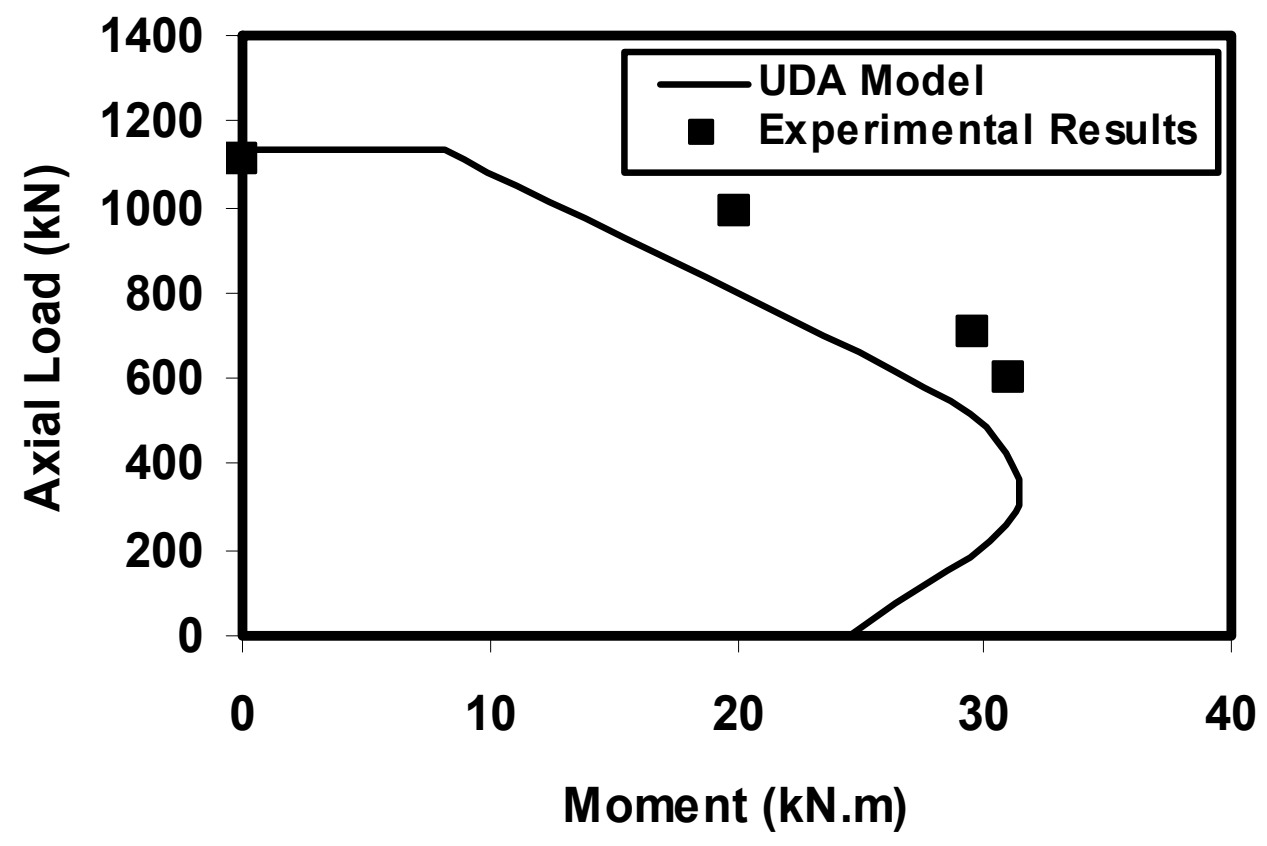

Fig. 9 Validation of the interaction diagram generated by UDM with experimental results [11] 


\section{Parametric Studies on the UDM}

The major parameters affecting the behavior of steel cased-concrete composite beam-columns are described in the following section. The first parameter includes the effect of concrete strength on the interaction diagram generated by the UDM for steel cased-concrete composite. The second parameter embraces the outcome plate with different thicknesses to generate interaction diagram. The first parameter deals with concrete while the second one deals with steel-case. The effect increasing of concrete strength on the strength interaction diagram is shown on Fig. 10. The concrete strength varies from $20 \mathrm{MPa}$ up to $40 \mathrm{MPa}$. As shown from Fig. 10. the increase of concrete strength is highly effective in the compression -controlled or in the transition zone. This increase is limited up to concrete strength of $35 \mathrm{MPa}$, which represents approximately the boarder between normal and high strength concrete.

The effect increasing of steel case thickness on the strength interaction diagram is shown on Fig. 11. The steel case thickness varies from $3 \mathrm{~mm}$ up to $5 \mathrm{~mm}$. As shown from Fig. 11. the increase of steel case thickness is most effective on tensioncontrolled design zone. For the compression-controlled and transition zone this increase is quite small in comparison with the increase in the compression-controlled or tension zone. Also, it was found that the thickness of steel case is highly effective in the confinement of concrete up to thickness of $4 \mathrm{~mm}$ after this thickness the confinement effect of the steel case is quite disregarded value. For this reason, if the design was carried out in the compression-controlled or in the transition zone the increase of the concrete strength is the optimum choice, while if the design was carried out in the tension-controlled the increase of the steel plate thickness is the most pronounced choice.

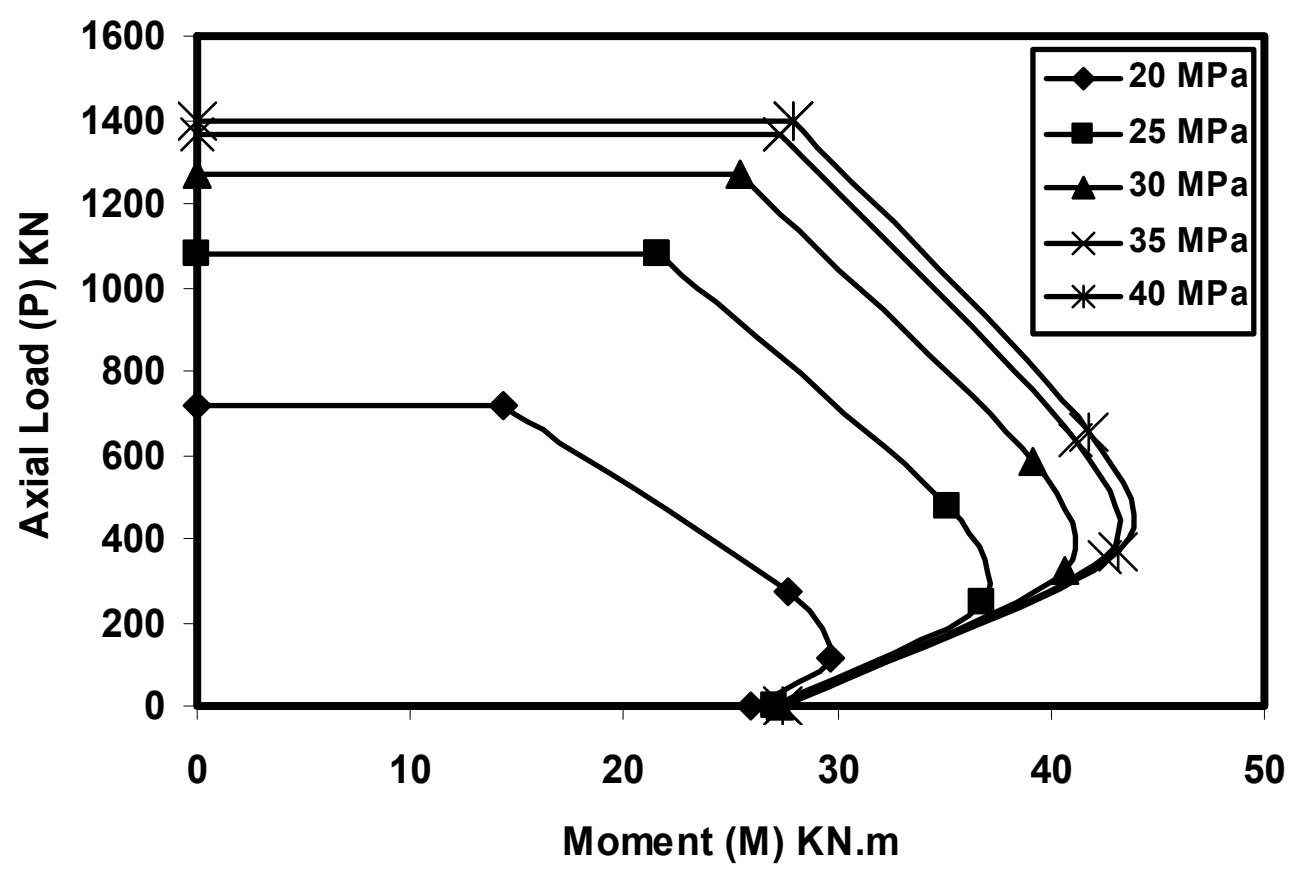

Fig. 10 Tension Controlled definition of steel cased-concrete box with eccentric load 


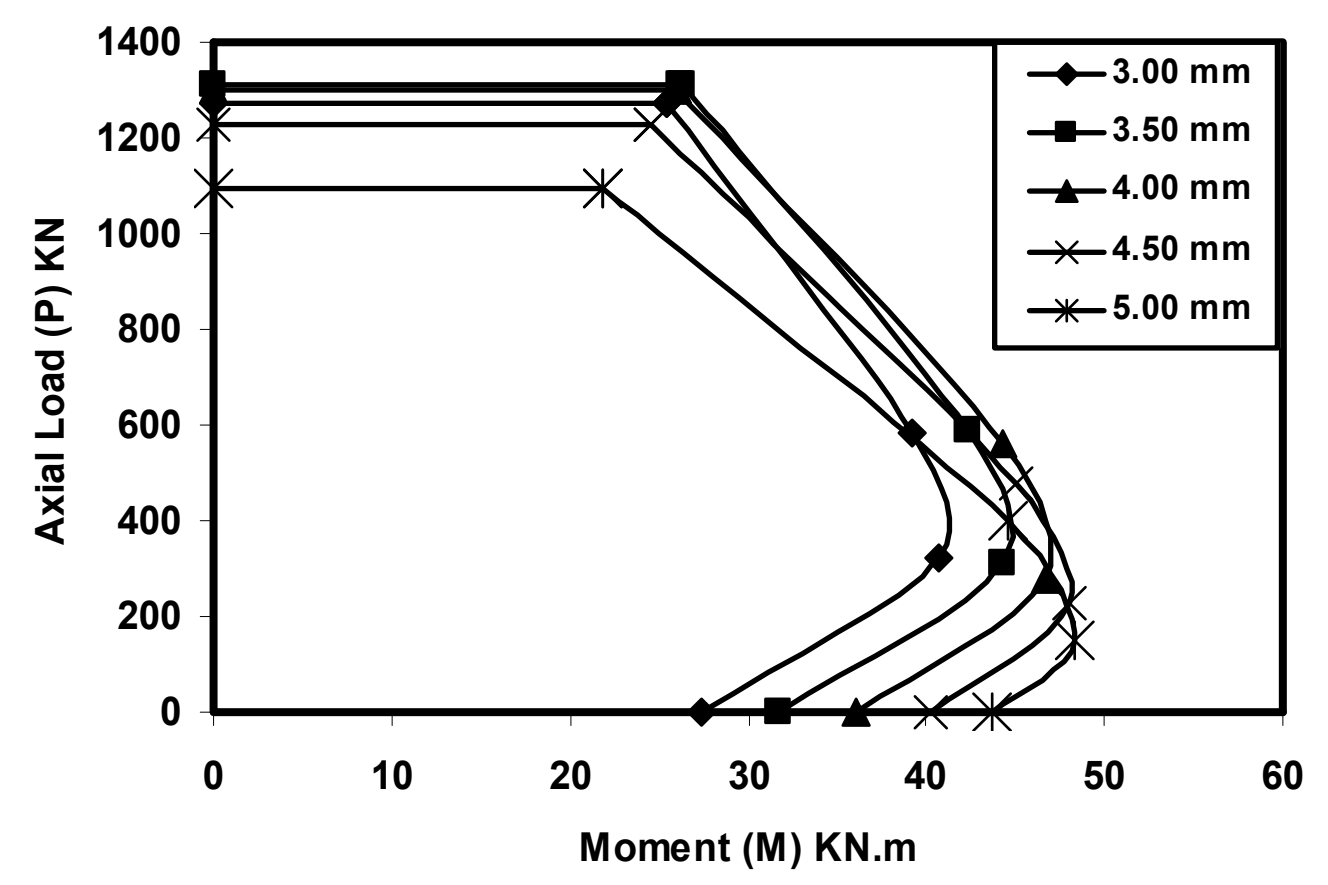

Fig. 11 Tension Controlled definition of steel cased-concrete box with eccentric load

\section{Conclusion}

In this paper the application of the unified design methodology for steel caseconcrete composite column was performed on circular and square cross section. These circular and square sections are subjected to axial load with minimum eccentricity. The following conclusive points are derived from this paper as:

1. Using the partial safety factors of materials $\left(\gamma_{c}, \gamma_{s}\right)$ proposed in this paper instead of the strength reduction factor $(\phi)$ used in the $\mathrm{ACl}$ Code. The limit of extreme tensile strain for compression controlled sections is chosen 0.0018 instead of 0.002 by the $\mathrm{ACl}$ Code because $\left(\gamma_{\mathbf{s}}\right)$ is involved in calculating strains according to the Egyptian Code.

2. Tension controlled sections are designed with smaller values of the strength reduction factors of concrete and steel than those considered for either compression controlled sections or sections fall in the transition zone. That is because the tension controlled sections are expected to give adequate warning of impending failure prior to actual collapse and they are less sensitive to variation in material strengths, especially to the concrete strength.

3. A computer program is implemented in this paper to generate the strengthinteraction diagram. An acceptable agreement between UDM method and the experimental results was clear. The main advantage of the UDM is to insure the behavior of column in compression controlled and the beam-column in 
tension or in compression or in transition controlled. Parametric study was performed to account for the main parameters on the major aspects of the UDM analytical method.

4. The increase of concrete strength is highly effective in the compression controlled or in the transition zone. This increase is limited up to concrete strength of $35 \mathrm{MPa}$, which represents approximately the boarder between normal and high strength concrete.

5. The increase of steel case thickness is most effective on tension-controlled design zone. For the compression-controlled and transition zone this increase is quite small in comparison with the increase in the compression-controlled or tension zone. Also, it was found that the thickness of steel case is highly effective in the confinement of concrete up to thickness of $4 \mathrm{~mm}$ after this thickness the confinement effect of the steel case is quite disregarded value.

6. It is highly recommended that if the design was carried out in the compression-controlled or in the transition zone the increase of the concrete strength is the optimum choice, while if the design was carried out in the tension-controlled the increase of the steel plate thickness is the most pronounced choice.

\section{References}

[1] American Concrete Institute (ACI), (1999). "Building Code Requirements for Structural Concrete (ACl 318-99) and Commentary". AC 318-99, Farmington Hills, Mich.

[2] American Institute of Steel Construction (AISC), (1999). "Load and Resistance Factor Design (LRFD)", Specifications for Structural Steel Buildings, Chicago.

[3] Varma, A.H., Ricles, J.M., Sause, R., and Lu, L.W., "Experimental Behavior of High Strength Square Concrete-Filled Steel Tube Beam-Columns", ASCE, J., V. 128 , No. 3, 2002, pp. 309-318.

[4] "The Egyptian Code of Practice for Design and Construction of Concrete Structures (ECP203-2007)", 2007.

[5] Naaman A. E., "Unified Design Recommendations for Reinforced, Prestressed and Partially Prestressed Concrete Bending and Compression Members", ACl Structural Journal V. 89, No. 2, March-April 1992, pp. 200-210.

[6] Mast, R. F., "Unified Design Provisions for Reinforced and Prestressed Concrete Flexural and Compression Members", ACI Structural Journal V. 89, No. 2, March-April 1992, pp. 185-199.

[7] Kenny, J.R., Bruce, D.A., and Bjorhovde, R., "Removal of Yield Stress Limitation for Composite Tubular Columns", Eng. J., AISC, First Quarter, 1994, pp. 1-11.

[8] Bradford, M.A., "Design Strength of Slender Concrete-Filled Rectangular Steel Tubes", ACI J., V. 93, No. 2, 1996, pp.229-235.

[9] Itani, A.M., "Fracture Use of Composite Steel-Concrete Columns in Highway Bridges", Eng. J., AISC, Third Quarter, 1996, pp. 110-115.

[10] Zhang, W., and Shahrooz, B.M., "Strength of Short and Long Concrete-Filled Tubular Columns", ACl J., V. 96, No. 2, 1999, pp. 230-238. 
[11] Brain, U., "Strength of Concrete Filled Steel Box Columns Incorporating Local Buckling", ASCE, J., V. 126, No. 3, 2000, pp. 341-352.

[12] Lakshmi, B., and Shanmugam, N.E., "Nonlinear Analysis of In-Filled SteelConcrete Composite Columns", ASCE J., V, 128, No. 7, 2002, pp. 922-933.

[13] Huang, C.S., Yeh, Y.K., Liu, G.Y., Hu, H.T., Tsai, K.C., Weng, Y.T., Wang, S.H., and Wu, M.H., "Axial Load Behavior of Stiffened Concrete-Filled Steel Columns", ASCE J., V. 128, No. 9, 2002, pp. 1222-1230.

[14] Khalifa, E.S., and El-Abbasy, A.A., "Analytical Model of High-Strength Concrete Filled Steel Box Beams", Tenth International Colloquium on Structural and Geotechnical Engineering, Ain Shams University, Cairo, Egypt, E03ST0, 2003, pp. 1-15.

[15] Hardika, M.S., and Gardner, N.J., "Behavior of Concrete-Filled Hollow Structural Section Beam Columns to Seismic Shear Displacements", ACI J., V. 101 , No. 1, 2004, pp. 39-46.

[16] Khalifa, E.S., and El-Abbasy, A.A., "Behavior of Beam-Column Steel Box Filled with High-Strength Concrete", Fourth International Colloquium on Engineering, Mansoura University, Mansoura, Egypt, IEC-C, 2004, pp. 163179.

[17] Bing, L., Park, R., and Tanaka, H., "Stress-Strain Behavior of High-Strength Concrete Confined by Ultra-High-and Normal-Strength Transverse Reinforcement", ACI J., V. 98, No. 3, 2001, pp. 395-406.

[18] Khalifa, E.S., and El-Abbasy, A.A., "Unified Design Approach for Analysis of Fibrous Concrete Flexural Members", Ain Shams Scientific Bulletin, Ain Shams University, Cairo, Egypt, Accepted for Publication. 